\title{
Research Article \\ DC Electrical Ageing of XLPE under Hydrostatic Pressure
}

\author{
Fadila Benlizidia Lalam and Faouzi Djemmal \\ Quantum Chemistry and Physics Laboratory, Mouloud Mammeri University, Tizi-Ouzou, Algeria \\ Correspondence should be addressed to Fadila Benlizidia Lalam; flalam@yahoo.fr
}

Received 13 December 2016; Revised 27 February 2017; Accepted 7 March 2017; Published 20 March 2017

Academic Editor: Antonio Riveiro

Copyright (C) 2017 Fadila Benlizidia Lalam and Faouzi Djemmal. This is an open access article distributed under the Creative Commons Attribution License, which permits unrestricted use, distribution, and reproduction in any medium, provided the original work is properly cited.

\begin{abstract}
The experimental electrical ageing, of cross-linked polyethylene films $100 \mu \mathrm{m}$ thick, was investigated under high hydrostatic pressure of 300 bar and at atmospheric pressure. The tests are conducted on direct current (dc) for up to $1000 \mathrm{~h}$ ageing and at temperature of $70^{\circ} \mathrm{C}$. The use of the Weibull statistic, with the estimation of confidence bounds at $90 \%$, has shown that the hydrostatic pressure has a real effect on the lifetime. These lifetime data are qualitatively analyzed with the inverse power model. It was found that thermally activated process is able to describe the pressure effect on the electrical ageing of XLPE.
\end{abstract}

\section{Introduction}

Since the advent of synthetic polymer development, crosslinked polyethylene (XLPE) has become the commonly used insulating material for modern high-voltage extruded cables, due to a combination of low material and processing costs, reliability, and appropriate electrical and mechanical properties [1,2]. This widespread use of XLPE may be attributed also to a maximum operation temperature of $90^{\circ} \mathrm{C}$, emergency temperature of $130^{\circ} \mathrm{C}$, and a short circuit maximum temperature of $250^{\circ} \mathrm{C}[3,4]$.

However, it is well known that, under service conditions, these insulators will likely undergo a graduation deterioration in performance as a dielectric material that can ultimately lead to failure. Consequently, the study of this phenomenon, namely, electric ageing, or a long-term dielectric breakdown, of these materials, is necessary. The interest of such a study is double: on the one hand, it allows the evaluation of the time to breakdown or lifetime of these insulators under the effect of the considered stresses; on the other hand, it looks for a correlation between the ageing process and the stresses causing it.

The main purpose of our work has therefore been to examine the effect of hydrostatic pressure, on the electrical ageing, by a dc voltage, on insulators used in submarine cables. We have already investigated this effect on other insulators polymers [5]. This paper gives the long-term performance of XLPE films at a temperature of $70^{\circ} \mathrm{C}$ and two pressures: 1 and 300 bar. These parameter values (300 bar and $70^{\circ} \mathrm{C}$ ) can be considered as the real use conditions of the submarine cables.

\section{Experimental Procedure}

2.1. Materials under Study. The samples, which were $100 \mu \mathrm{m}$ thick films of XLPE, were cut from unaged cables. The insulation thickness was precisely controlled by micrometer. The principal characteristics of these XLPE specimens are given in Table 1. Commercial confidentiality denied us knowledge of the manufacturing procedure.

2.2. Experimental Setup. The purpose of our work is to show the effect of hydrostatic pressure on the electrical ageing, by a dc voltage, on XLPE and that is why the experimental study has been carried out at two pressures: 1 bar and 300 bar and the temperature of $70^{\circ} \mathrm{C}$. The latter can be considered as the temperature of XLPE insulator in service condition.

The experimental setup is classically composed of a dc generator of $100 \mathrm{kV}$, a measuring cell, and a detection system.

The samples were placed into the measuring cell composed of five high-voltage relays and five pairs of electrodes. Electrodes are made with stainless steel following Rogowsky profile. The same dc voltage (ranging from 14 to $50 \mathrm{kV}$ ) was applied to each specimen (they were tested in parallel). When a dielectric breakdown occurred in a sample, a positive 


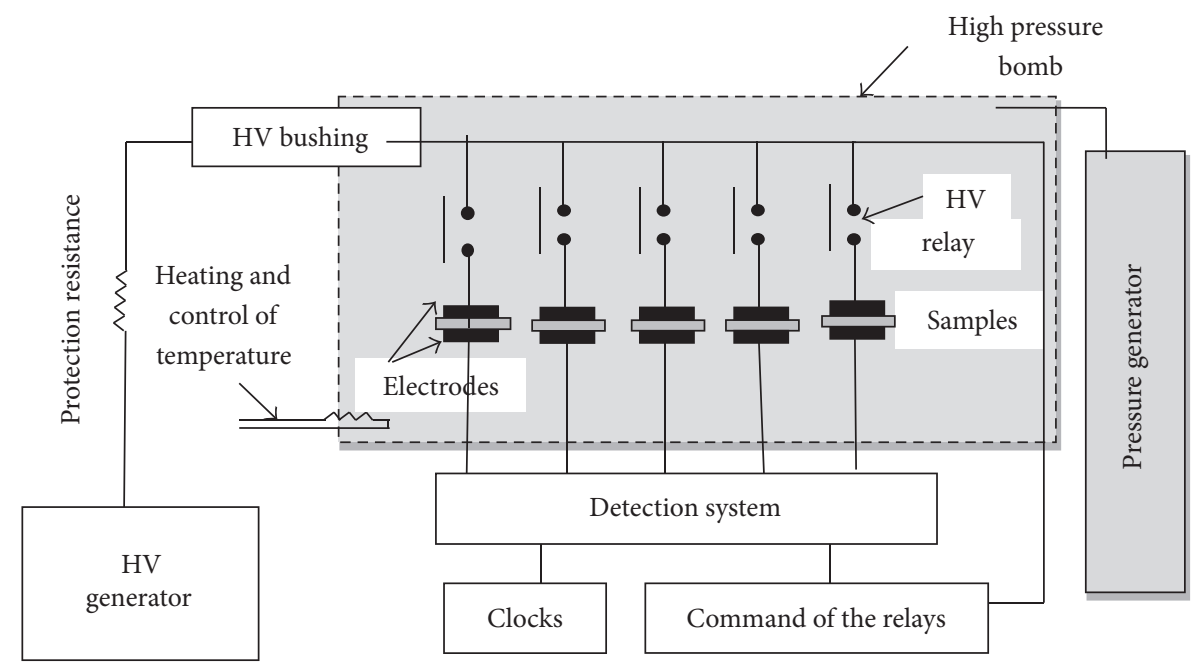

FIGURE 1: Electrical ageing measurement setup under hydrostatic pressure.

TABLE 1: Main characteristics of XLPE under study.

\begin{tabular}{lc}
\hline Density & 0.923 \\
Melting point $\left({ }^{\circ} \mathrm{C}\right)$ & 110 \\
Rate of crystallinity & 40 \\
Tensile strength $(\mathrm{MPa})$ & 17 \\
Elongation $(\%)$ & 450 \\
Water content $(\mathrm{ppm})$ & 100 \\
Dielectric constant $\varepsilon_{r}(1 \mathrm{MHz})$ & 2.3 \\
Loss factor & $5 \cdot 10^{-4}$ \\
\hline
\end{tabular}

pulse was generated across the detection system by which the applied voltage was immediately removed for this sample and the breakdown time value, $t_{i}$, was recorded.

For high-pressure measurements (300 bar), the measuring cell was placed into a high-pressure bomb with a working volume of $9500 \mathrm{~cm}^{3}$, where the pressure was obtained by a diaphragm compressor using gaseous nitrogen as the transmitting fluid. At atmospheric pressure (1 bar), the measuring cell was immersed into a chamber filled with silicone oil to avoid flashover and partial discharge effects.

For all measurements, the desired temperature was obtained, with stability of $1^{\circ} \mathrm{C}$, by the use of heating resistance of $1600 \mathrm{~W}$.

A schematic drawing of the experimental setup, under hydrostatic pressure, is shown in Figure 1.

\section{Results and Discussion}

Experimental results were obtained at 1 and 300 bar, for a temperature of $70^{\circ} \mathrm{C}$ in the range of an electrical field of $140-450 \mathrm{kV} \cdot \mathrm{mm}^{-1}$ and for up to $1000 \mathrm{~h}$ of ageing. For each value of field, only five specimens were aged since it takes a relatively long time to perform one measurement.
3.1. Statistical Analysis. To assess the results for the breakdown of polymeric insulation, the use of statistical method is often required. Weibull distribution is now widely accepted which is based on the fact that the failure of the whole system depends on the failure of the weakest point in the system $[6,7]$. The two-parameter Weibull distribution is given by

$$
F(t)=1-\exp \left[-\left(\frac{t}{\alpha}\right)^{\beta}\right],
$$

where $t$ is the measured breakdown time; $F(t)$ is the probability of failure at time less than or equal to $t ; \alpha$ is the scale parameter $(\alpha>0)$ and represents the time for which the failure probability is $63.2 \%$; and $\beta$ is a shape parameter and a measure of the spread of the data.

The time to breakdown data and tolerance bounds on percentiles, of the two-parameter Weibull distribution, were then fitted using an exact approach based on the maximum likelihood method [8].

Figures 2 and 3 give examples of the application of the Weibull distribution to our experimental data. The same types of graph were obtained for the other values of electrical fields. They show that the $90 \%$ confidence bounds (for 1 and 300 bar) do not overlap, indicating that the two sets of data are different significantly.

Even though the distribution of Weibull does not offer any physical mechanism of electric ageing, it remains essential for the analysis of the experimental data and the description of the effect of a parameter (pressure in our case). To explain the effect of pressure on the electrical ageing of XLPE, we try to model the experimental lifetime data. The models suggested in the literature are of two types: macroscopic and microscopic. The first one or phenomenological one can be considered as global description of ageing, while the second one is based on a physical approach.

3.2. The Inverse Power Law Model. The inverse power law model is an empirical model, but it is commonly used for a 


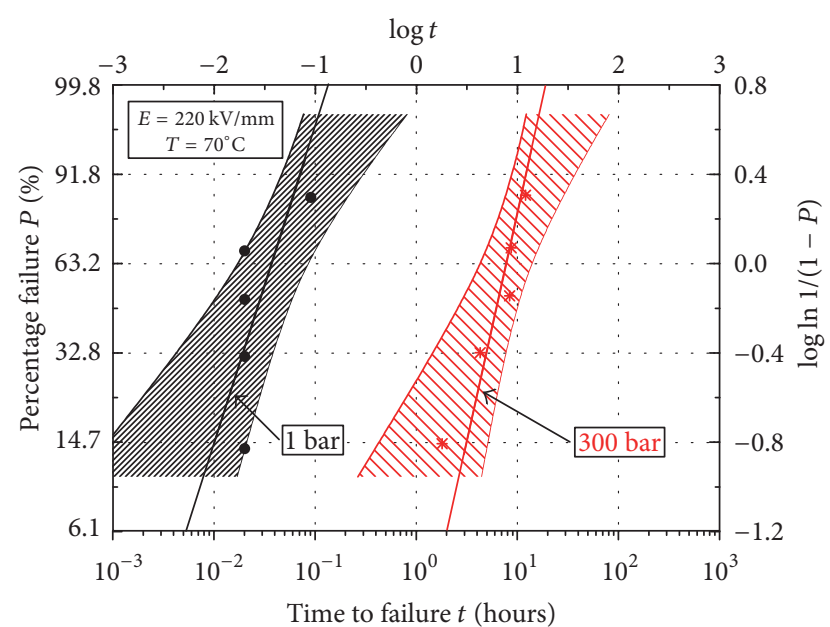

FIgURE 2: Weibull plot of the electrical ageing data of XLPE at $220 \mathrm{kV} / \mathrm{mm}$ and $70^{\circ} \mathrm{C}$.

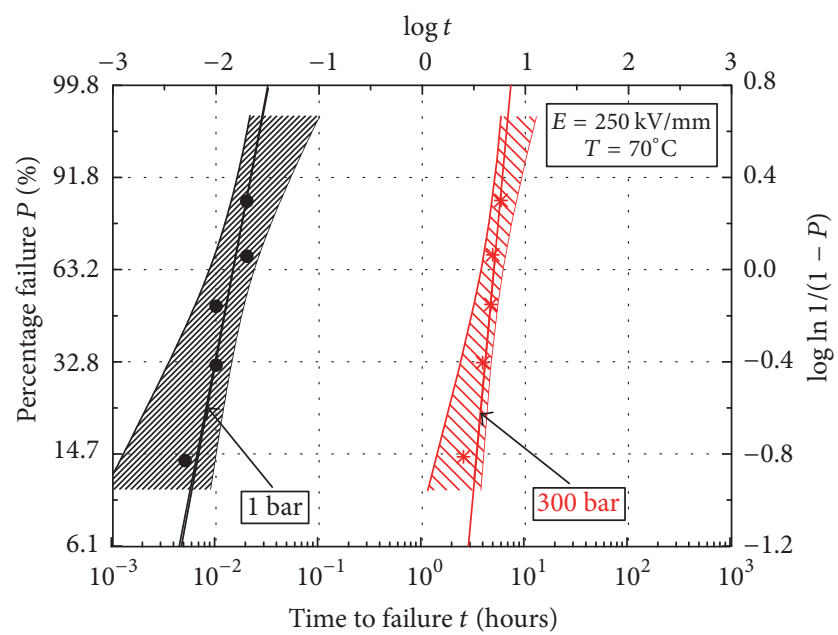

Figure 3: Weibull plot of the electrical ageing data of XLPE at $250 \mathrm{kV} / \mathrm{mm}$ and $70^{\circ} \mathrm{C}$.

qualitative analysis $[9,10]$. It is given by the following relationship:

$$
t=k E^{-n},
$$

where $t$ is the time to breakdown (usually it is a Weibull scale at $63.2 \%$ probability); $E$ is the applied electrical field; $k$ is a constant; the exponent $n$ is the voltage endurance coefficient whose value depends on the compound, additives, and manufacturing procedures [11].

The inverse power law is considered valid, if the data being plotted on log-log graph fits a straight line.

Figure 4, which gives the fit of our experimental data, for the two considered pressures, shows the following:

(i) The reduction of the life exponent $n$, with pressure, is from $n(1 \mathrm{bar})=18$ to $n(300 \mathrm{bar})=12$. The recommendation, for testing high-voltage dc extruded cables systems, gives lower limit of ageing parameter $n$ equal to 10 [12].

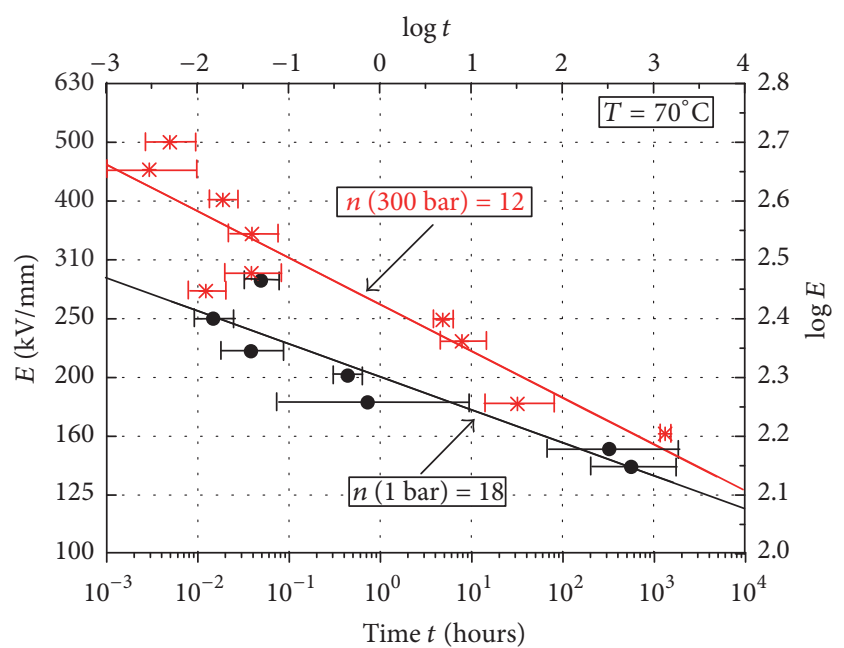

FIGURE 4: Representation of the ageing data of XLPE, according to the inverse power model, at 1 and 300 bar and $70^{\circ} \mathrm{C}$. The bars to each line in this plot are $90 \%$ confidence limits.

(ii) The life curve at 300 bar is shifted towards the high fields.

3.3. Application of Crine's Model. The inverse power law model has no clear physical basis; it allows a qualitative analysis but does not give information on the origin of the breakdown processes [13]. Among the physical theories studied in our bibliography, it seems that Crine's model is adapted the most to describe our results.

This electrical life model, presented in the last three decades and modified later, assumes that electrical ageing is thermally activated process [13-17]. It was the first model to use the thermodynamic concept associated with the theory rate to describe ageing process [18]. Indeed, the energy parameter controlling the rate of ageing is the free energy change $\Delta G=\Delta H-T \Delta S$, where $\Delta H$ and $\Delta S$ are the activation enthalpy and entropy [19]. Thus, a free energy barrier $\Delta G$ shall be crossed for the system to pass from the unaged state to the aged state. Under the action of electrical field, the barrier $\Delta G$ decreases with the square of the field due to an electromechanical modification of the intrinsic free energy barrier. Then, the insulation life under dc high field $E$ is given by

$$
t \approx\left[\frac{h}{2 k T}\right] \exp \left[\frac{\Delta G-(1 / 2) \varepsilon_{0} \varepsilon_{r} \Delta V E^{2}}{k T}\right],
$$

where $h$ and $k$ are the Planck and Boltzmann constant, $\Delta V$ is the activation volume, $\varepsilon_{0}$ and $\varepsilon_{r}$ are the permittivity of free space and the dielectric constant of polymer, respectively.

This model suggested that the main ageing factor is the Maxwell stress induced by the field [17, 20]. Under the action of low and moderate electrical field, the nanocavities (the free volume of polymers) will be compressed by this compressive Maxwell stress. In this case only some nanocavities will be deformed and those located near chain ends and in the amorphous phase are more likely to be the first to be deformed. When a given number of nanocavities have been entirely 
TABLE 2: Parameters of Crine's model for the ageing of XLPE at $70^{\circ} \mathrm{C}$.

\begin{tabular}{lcc}
\hline Pressure (bar) & $\Delta G(\mathrm{~J})$ & $\Delta V\left(\mathrm{~m}^{3}\right)$ \\
\hline 1 & $2,3 \cdot 10^{-19}$ & $1,2 \cdot 10^{-25}$ \\
300 & $2,35 \cdot 10^{-19}$ & $0,837 \cdot 10^{-25}$ \\
\hline
\end{tabular}

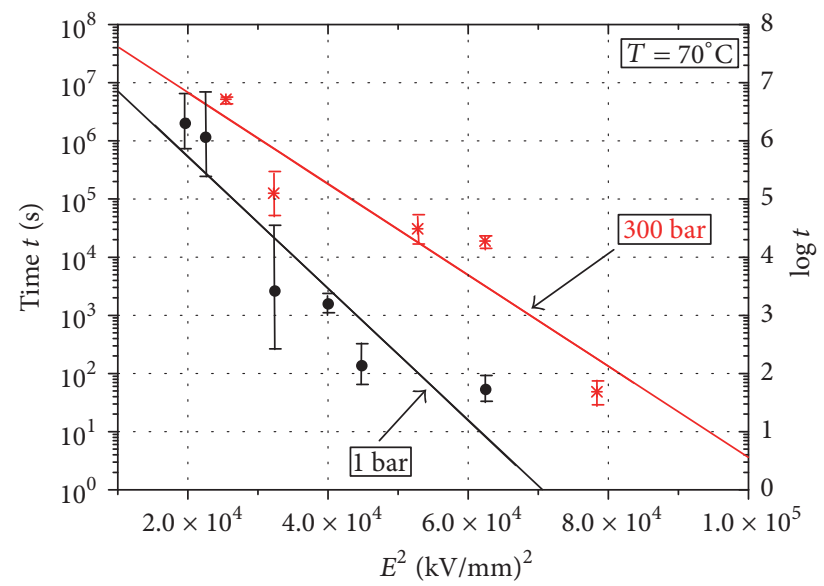

FIGURE 5: Representation of the experimental data of the XLPE at $70^{\circ} \mathrm{C}$, according to Crine's model.

deformed, the amorphous phase is then significantly deformed and weak Van der Waals attraction bonds are broken; then the ageing process will considerably accelerate. The activation volume is then the inverse of the concentration of completely deformed nanocavities.

This model envisages a linear relation between $E^{2}$ and the logarithm of time (3), which we obtained with our results on Figure 5. Table 2 gives the value of $\Delta V$ and $\Delta G$ deduced from the slope and intercept, respectively, in these plots.

The free energy and the activation volume values deduced from experimental results (Table 2) seem in good agreement with existing data $[17,20]$.

The increase of $\Delta G$, with pressure, can be attributed to the term $P \Delta V$ which appears in the relation of $\Delta G(\Delta G=\Delta H-$ $T \Delta S=\Delta E-T \Delta S+P \Delta V)$ and which is generally negligible at atmospheric pressure [21]. The deformation of the barrier has been also reported by Crine and David [22]. They found that under a hydrostatic pressure $P$ the barrier is deformed symmetrically (the original and final states are equally deformed by the energy term $P \Delta V$ ).

The decrease of $\Delta V$ with the pressure can be explained by the fact that the hydrostatic pressure induces a compression which reduces the free volume of the polymer; it has been reported that the hydrostatic pressure can change the free volume and the morphology of polymers [23].

\section{Conclusion}

The pressure effect on the electrical ageing of XLPE films has been investigated. The experimental measurements were carried out at pressures of 1 and 300 bar, at temperature of $70^{\circ} \mathrm{C}$, in the range of an electrical field of $140-450 \mathrm{kV} / \mathrm{cm}$, and for up to 1000 hours of ageing. The results were analyzed by
Weibull's statistic with a confidence bounds of a $90 \%$ level. The inverse power law model gives a qualitative analysis: the hydrostatic pressure delays the electrical ageing of this XLPE in the time domain considered. The ageing process of this polymer could be explained by Crine's model based on the concept of thermally activated degradation and the existence of nanocavities. We assume that both of them can be influenced by an increase of hydrostatic pressure.

\section{Conflicts of Interest}

The authors declare that there are no conflicts of interest regarding the publication of this paper.

\section{References}

[1] X. R. Chen, L. B. Hu, Y. Xu, X. L. Cao, and S. M. Gubanski, "Investigation of temperature effect on electrical trees in XLPE cable insulation," in Proceedings of the Annual Report Conference on Electrical Insulation and Dielectric Phenomena (CEIDP '12), pp. 612-615, Montreal, Canada, October 2012.

[2] T. L. Hanley, R. P. Burford, R. J. Fleming, and K. W. Barber, "A general review of polymeric insulation for use in HVDC cables," IEEE Electrical Insulation Magazine, vol. 19, no. 1, pp. 13-24, 2003.

[3] V. Vahedy, "Polymer insulated high voltage cables," IEEE Electrical Insulation Magazine, vol. 22, no. 3, pp. 13-18, 2006.

[4] A. M. Nobrega, M. L. B. Martinez, and A. A. A. De Queiroz, "Investigation and analysis of electrical aging of XLPE insulation for medium voltage covered conductors manufactured in Brazil," IEEE Transactions on Dielectrics and Electrical Insulation, vol. 20, no. 2, pp. 628-640, 2013.

[5] F. Benlizidia Lalam and T. G. Hoang, "Pressure effect on the electrical ageing of polyethylene," Journal of Physics D: Applied Physics, vol. 33, no. 22, pp. L133-L136, 2000.

[6] W. Weibull, "A statistical distribution function of wide applicability," Journal of Applied Mechanics, vol. 18, pp. 293-297, 1951.

[7] IEEE, "IEEE guide for the statistical analysis of electrical insulation voltage endurance data," IEEE Standard 930-1987, 1998.

[8] G. C. Stone and J. F. Lawless, "The application of weibull statistics to insulation aging tests," IEEE Transactions on Electrical Insulation, vol. EI-14, no. 5, pp. 233-239, 1979.

[9] P. Cygan and J. R. Laghari, "Models for insulation aging under electrical and thermal multistress," IEEE Transactions on Electrical Insulation, vol. 25, no. 5, pp. 923-934, 1990.

[10] L. Simoni, "A general approach to the endurance of electrical insulation under temperature and voltage," IEEE Transactions on Electrical Insulation, vol. 16, no. 4, pp. 277-289, 1981.

[11] G. Mazzanti and M. Marzinotto, Extruded Cables for HighVoltage Direct-Current Transmission, John Wiley \& Sons, Hoboken, NJ, USA; 2013.

[12] T. Liu, Z. Lv, Y. Wang et al., "A new method of estimating the inverse power law ageing parameter of XLPE based on stepstress tests," in Proceedings of the Annual Report Conference on Electrical Insulation and Dielectric Phenomena, pp. 69-72, Shenzhen, China, October 2013.

[13] J. Crine, J. Parpal, and G. Lessard, "A model of aging of dielectric extruded cables," in Proceedings of the 3rd International Conference on Conduction and Breakdown in Solid Dielectrics, pp. 347351, Trondheim, Norway, July 1989. 
[14] C. Dang, J.-L. Parpal, and J.-P. Crine, "Electrical aging of extruded dielectric cables: review of existing theories and data," IEEE Transactions on Dielectrics and Electrical Insulation, vol. 3, no. 2, pp. 237-247, 1996.

[15] J. P. Crine, "A model of solid dielectric aging," in Proceedings of the Conference Record of the 1990 IEEE International Symposium on Electrical Insulation, pp. 25-26, Toronto, Canada, 1990.

[16] J. P. Crine, "The compensation law and polymer aging relaxations," in Proceedings of the 3rd International Conference on Conduction and Breakdown in Solid Dielectrics, pp. 321-325, 1989.

[17] J.-P. Crine, "On the interpretation of some electrical aging and relaxation phenomena in solid dielectrics," IEEE Transactions on Dielectrics and Electrical Insulation, vol. 12, no. 6, pp. 10891107, 2005.

[18] H. A. Alghamdi, G. Chen, and A. S. Vaughan, "Comparison of two schools of polymeric ageing models: causes and effects of space charge," in Proceedings of the IEEE Conference on Electrical Insulation and Dielectric Phenomena (CEIDP '12), pp. 827-830, Montreal, Canada, October 2012.

[19] J. P. Crine, "On the use of rate theory to understand the aging of dielectrics," in Proceedings of the International Conference on Properties and Applications of Dielectric Materials, pp. 214-217, 1985.

[20] J. P. Crine, "A molecular model for the electrical aging of XLPE," in Proceedings of the Conference on Electrical Insulation and Dielectric Phenomena (CEIDP '07), pp. 608-610, October 2007.

[21] P. Destruel, Contribution à l'étude des propriétés diélectriques des polymères en fonction de leur histoire thermodynamique [Ph.D. thesis], Paul Sabatier University, Toulouse, France, 1980.

[22] J. P. Crine and E. David, "Influence of mechanical stresses on some electrical properties of polymers," in Proceedings of the Annual Report Conference on Electrical Insulation and Dielectric Phenomena, pp. 71-74, 2005.

[23] S. Li, W. Wang, S. Yu, and H. Sun, "Influence of hydrostatic pressure on dielectric properties of polyethylene/aluminum oxide nanocomposites," IEEE Transactions on Dielectrics and Electrical Insulation, vol. 21, no. 2, pp. 519-528, 2014. 

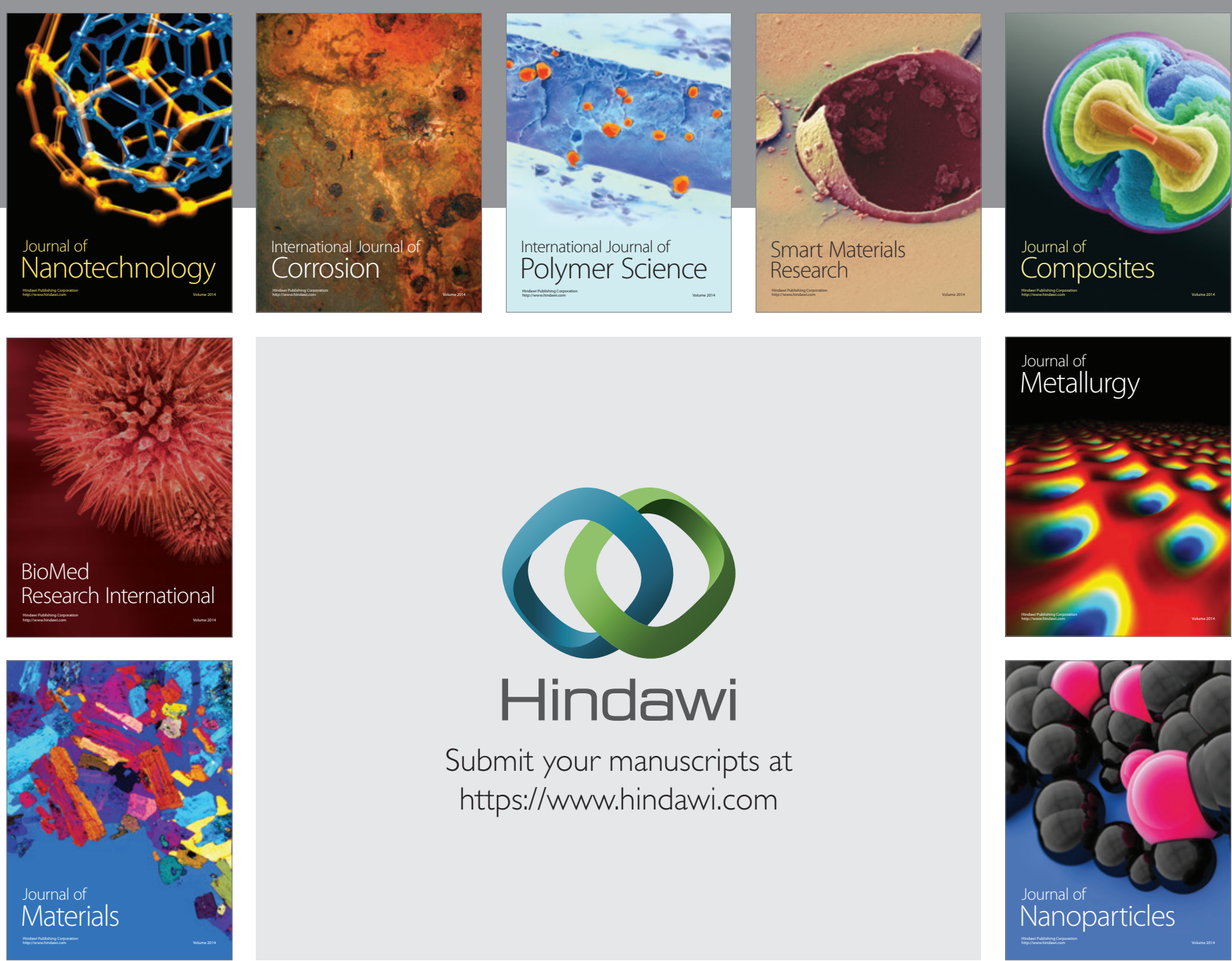

\section{Hindawi}

Submit your manuscripts at

https://www.hindawi.com

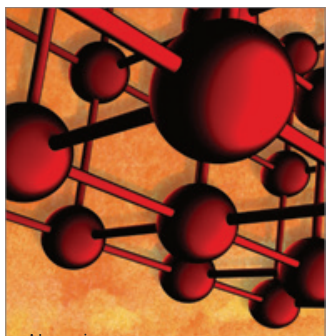

Materials Science and Engineering
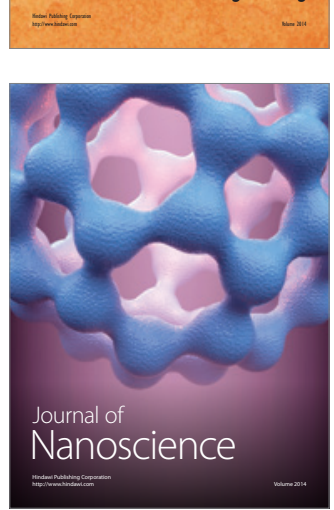
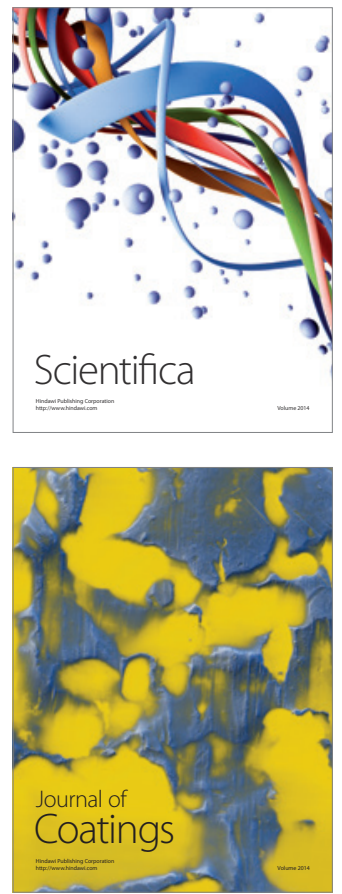
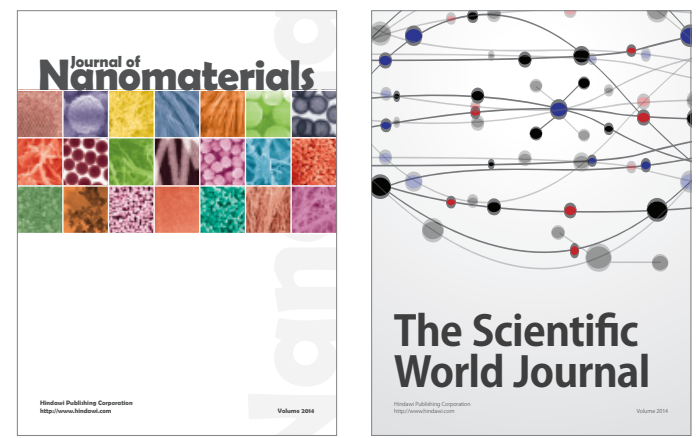

The Scientific World Journal
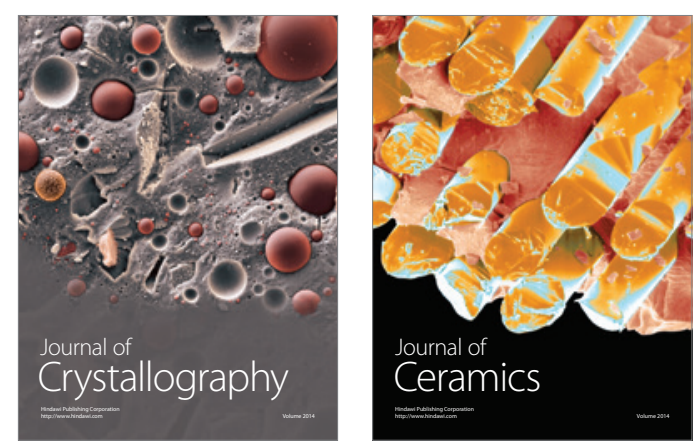
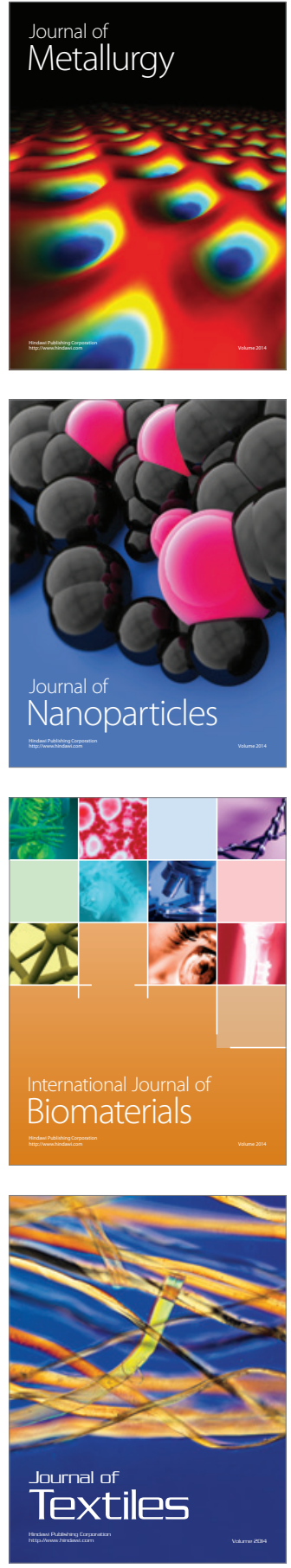